- Gratificação concedida ao pessoal da ativa, com caráter de generalidade: sua extensão aos servidores aposentados: C.F., art. 40, $\$ 4^{2}$.

- A gratificação de Gestão e controle do Erário Estadual - GECE, instituída pela Lei Complementar paulista $n^{\circ}$ 700/92, apresenta caráter de generalidade, motivo por que estende-se aos inativos: C.F., art. 40, $\$ 4$.

- Precedente do STF: RE 206.083-SP, Galvão, $1^{a}$ Turma, "DJ" de 13-03-98

- R.E. conhecido e provido. 


\title{
SUPREMO TRIBUNAL FEDERAL
}

Recurso Extraordinário $\mathrm{n}^{\Perp 2} \mathbf{2 1 5 . 8 5 8}$

\author{
Recorrente: João Camillo e Aguiar \\ Recorrido: Departamento de Estradas de Rodagem do Estado de São \\ Paulo - DER/SP \\ Relator: Sr. Ministro CARLOS VELLOSO
}

\section{ACÓRDĀO}

Vistos, relatados e discutidos estes autos, acordam os Ministros do Supremo Tribunal Federal, em Segunda Turma, na conformidade da ata do julgamento e das notas taquigráficas, por decisão unânime, conhecer do recurso e lhe dar provimento, nos termos do voto do Sr. Ministro Relator. Ausentes, justificadamente, neste julgamento, os Srs. Ministros Presidente e Maurício Corrêa.

Brasília, 15 de dezembro de 1998.

CARLOS VELLOSO - Presidente e Relator

\section{RELATÓRIO}

O Sr. Ministro CARLOS VELLOSO: - A Quinta Câmara de Direito Público do Tribunal de Justiça do Estado de São Paulo, em ação sob o procedimento ordinário, por maioria de votos, decidiu que a Gratificação de Gestão e Controle do Erário Estadual GECE não é revestida do caráter de generalidade, dado que a Lei Complementar 700/92 que a instituiu, a fez em razão de condiçāo peculiares de trabalho e das unidades em que é exercido.

Interpostos embargos infringentes, foram eles rejeitados.

Daí o RE, interposto por servidores aposentados do Departamento de Estradas de Rodagem - DER, fundado no art. 102, III, $a$, da Constituição Federal, alegando violação ao art. 40, $\$ 40$, da mesma Carta.

Sustentam, em síntese, que a Lei Complementar 700/92, ao instituir a referida gratificação aos funcionários que desempenham funções tipicamente fazendárias, limitou seu percebimento elencando atribuições normais e rotineiras a todos os agentes fazendários. Assim, nos termos do art. $40, \S 4^{\circ}$, da CF/88, concedida a gratificação em decorrência da natureza do cargo, têm os servidores inativos direito ao acréscimo, nas exatas condições em que vêm sendo pago aos servidores em atividade.

Admitido o recurso, subiram os autos.

O Ministério Público Federal, no parecer da lavra do ilustre Subprocurador-Geral da República Dr. Roberto Monteiro Gurgel Santos, opina pelo provimento do recurso.

É o relatório.

\section{VOTO}

O Sr. Ministro CARLOS VELlOSO (Relator): O parecer da Procuradoria-Geral da República enfoca, com propriedade, a questāo:

\section{“(...)}

Trata-se de recurso extraordinário interposto de acórdão que negou a servidores públicos aposentados a gratificação de gestāo e controle do erário instituída por lei estadual após a promulgação da Constituição Federal de 1998 e concedida somente aos servidores ativos.

O Plenário desse Supremo Tribunal Federal posicionou-se no sentido de que "a extensão aos aposentados dos beneficios e vantagens posteriormente criados, como prevê o § $4^{2}$ do art. 40 da Constituição, é relativa aos de caráter geral, o que exclui situaçōes particulares, como é o caso da gratificação que se destina a compensar o servidor enquanto 
dura o exercicio de trabalho normal em locais anormais, assim considerados pela Lei e pelo Decreto. Nem todos os benefícios concedidos aos servidores em atividade são compatíveis com a situaçāo do aposentado, como é o caso das férias anuais e da gratificação paga "durante o exercício" em locais adversos." (ADIN no 778, Rel.: Min. PAULO BROSSARD, DJ 19/12/94, p. 35.180).

No julgamento do $R E n^{\underline{0}}$ 198.129, DJ 11/3/96, cuidando de matéria análoga à dos autos, o Relator, Ministro MARCO AURÉ$L I O$, manifestou-se no mesmo sentido do que ficou decidido no $A G(A g R g) n^{\circ} 141.189, D J$ 14/8/92, assim ementado: 'ISONOMIA -

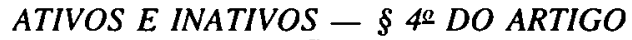
40 DA CONSTITUIÇÃO FEDERAL - APLICABILIDADE. A garantia insculpida no $\$ 4^{0}$ do artigo 40 da Constituição Federal é de eficácia imediata. A revisão dos proventos da aposentadoria e a extensão aos inativos de quaisquer beneficios e vantagens posteriormente concedidos aos servidores em atividade pressupõem tão-somente, a existência de lei prevendo-os em relação a estes últimos. $O$ silêncio do diploma legal quanto aos inativos não é de molde a afastar a observância da igualação, sob pena de releger-se o preceito constitucional a plano secundário, potencializando-se a atuação do legislador ordinário como se a este fosse possivel introduzir, no cenário jurídico, temperamentos à igualdade. Uma vez editada lei que implique outorga de direito aos servidores em atividade, dá-se, pela existência da norma constitucional, a repercussão no campo patrimonial dos aposentados. A locução contida na parte final do § $4^{\circ} \mathrm{em}$ comento - 'na forma da lei' apenas submete a situação dos inativos às balizas impostas na outorga do direito aos servidores da inativa'.

$E$, ao final daquele julgamento, observou:

'Dizer-se a esta altura, vulnerado o $\$ 4^{\circ} d o$ artigo 40 da Lei Básica, pressupõe o afastamento de duas premissas fáticas assinaladas pelo Tribunal de origem. A primeira está ligada ao campo de aplicação da lei local no que concerne ao pessoal da ativa. A segunda diz respeito ao fato de os Recorridos haverem se aposentado em cargo que está incluído dentre os beneficiados com a gratificação.'
Assim, opina o MINISTÉRIO PÚBLICO FEDERAL pelo provimento do recurso." (Fls. 314/316)

Correto o parecer.

Julgando caso igual - RE 206.083-SP, I1mar Galvão, 1 a Turma, 09.12.97, "DJ" de 13.0.98 - decidiu a $1^{\mathbf{a}}$ Turma:

"EMENTA: ADMINISTRATIVO. SERVIDORES INATIVOS DA SECRETARIA DE FAZENDA. GRATIFICAÇĀO DE GESTÃO E CONTROLE DO ERÁRIO ESTADUAL (GECE). LEI COMPLEMENTAR PAULISTA Ne $700 / 92$.

Vantagem remuneratória deferida, de forma geral, às categorias de servidores lotados na Secretaria da Fazenda do Estado; não configurando, nem gratificação de serviço, que contempla servidores que trabalham em condiçōes anormais de segurança, de salubridade ou de horário; nem gratificação pessoal, deferida a servidores sujeitos a encargos pessoais especificados em lei. Tampouco se trata de vantagem que tenha por pressuposto requisito que, forçosamente, somente na atividade, a partir de determinado momento projetado no futuro, possa vir a ser preenchido.

Manifesta ofensa ao art. 40, $\$ 4^{\circ}$, da CF.

Recurso conhecido e provido". ("DJ" de 13.3.98).

Destaco do voto do Relator, eminente Ministro Ilmar Galvão:

“(...)

No caso dos autos, ao que se colhe do texto da LC ñ 700/92 (fls. 315/324), não se está diante de gratificaçāo de serviço nem de gratificação pessoal, nem de vantagem que tenha por pressuposto requisito que, forcosamente, somente na atividade, a partir de determinado momento projetado no futuro, possa vir a ser preenchido, cuidando-se, antes, de estímulo deferido de forma geral às categorias de servidores lotados na Secretaria da Fazenda, conforme disposto no art. 22, in verbis:

'Art. 22 - Fica instituída Gratificação de Gestão e Controle do Erário Estadual GECE, em razão das características intrínsecas e da especificidade das unidades em que sāo desenvolvidas atividades de controle de arrecadação de tributos, controle financeiro, 
controle interno contábil do Poder Executivo, despesa de pessoal, controle das entidades descentralizadas, auditoria, bem como de formulação e execução da política de créditos e controle do patrimônio, exercidas pelos integrantes das classes constantes dos Anexos I e II a que se refere o artigo $1^{0}$ dessa lei complementar.'

Desinfluente, no caso, que, no art. 28, haja disposto o referido diploma legal que "a percepção das gratificaçōes previstas nos artigos $22 .$. desta lei complementar, cessará automaticamente quando o servidor deixar de ter exercicio na unidade em que incorreu sua concessão", nem, tampouco, que, segundo o art.-34, a incorporação da aludida gratificação aos proventos do servidor se dará à razão de $1 / 30$ por ano.

Pelo singelo motivo de não ser dado ao legislador ordinária editar norma jurídica que se oponha aos ditames da Constituição.

Apreciando questão análoga, acentuou o eminente Ministro Marco Aurélio, na decisão transcrita no parecer da douta ProcuradoriaGeral da República (fl. 345), que

'... O silêncio do diploma legal quanto aos inativos não é de molde a afastar a observância da igualação, sob pena de relegar-se o preceito constitucional a plano secundário, potencializando-se a atuaf̧ão do legislador ordinário como se a este fosse possível introduzir, no cenário jurídico, temperamentos à igualdade.'

$O$ mesmo raciocínio é de ser aplicado à hipótese dos autos, em que não houve propriamente silêncio do legislador acerca dos aposentados, mas expressa disposiçāo no sentido da incorporaçāo, apenas parcial, da vantagem aos proventos dos servidores por ela beneficiados, restriçāo que não é dado ao legislador ordinário estabelecer sem configurar desobediência à norma constitucional em tela.

$O$ acórdão recorrido, por dissentir desse entendimento, não tem condições de subsistir.

(...)"

Assim posta a questão, forte no precedente, conheço do recurso e dou-lhe provimento.

\section{EXTRATO DE ATA}

\section{RECURSO EXTRAORDINÁRIO №} 215.858-5

Proced.: São Paulo

Relator: Min. Carlos Velloso

Rectes.: João Camillo de Aguiar

Advdos.: Manuel dos Santos Fernandes Ribeiro e outros

Recdo.: Departamento de Estradas de Rodagem do Estado de São Paulo - DER/SP

Advdos.: Ivanny Fernandes de Freitas Hehl Prestes e outro

Decisâo: Por unanimidade, a Turma conheceu do recurso e lhe deu provimento, nos termos do voto do Relator. Ausentes, justificadamente, neste julgamento, os Senhores Ministros Presidentes e Maurício Corrêa. Presidiu, este julgamento, o Senhor Ministro Carlos Velloso. 2a Turma, 15.12.98.

Presidência do Senhor Ministro Néri da Silveira. Presentes à Sessão os Senhores Ministros Carlos Velloso, Marco Aurélio, Maurício Corrêa e Nelson Jobim.

Subprocurador-Geral da República, Dr. Mardem Costa Pinto.

Carlos Alberto Cantanhede - Coordenador 